\title{
Motivações Cognitivas e Interacionais em Competição: A Força das Palavras em Contexto
}

(Competition Among Cognitive and Interactional Motivations:

The Words'strength in Context)

\author{
Denize Elena Garcia Da SiLVA \\ (Universidade de Brasilia)
}

\begin{abstract}
In this article, I take the traditional concept of context, conceived by Malinowiski and discuss the parameters of this functional category, not only in terms of its exteriority but its association with internal cognitive models. Critical discourse analysis focusing on the language as a social practice is my theoretical passport, and teaching discourse is the object of my analysis and reflection. By searching for the explicit competition between cognitive and interactional motivations inside the classroom, I aim to show the strength of words in the "experience"or model that one carries within oneself, sometbing which must be cosidered during pedagogical action.
\end{abstract}

KEY-WORDS: Context; Cognition; Interaction; Discourse Analysis.

REsumo: Neste artigo, parto da noção clássica de "contexto" desde os estudos de Malinowiski, discutindo os parâmentros dessa categoria funcional não só em termos de sua exterioridade mas, principalmente, sua associaşão a modelos cognitivos interiorizados. A análise do discurso crítica que enfoca a língua como prática social constitui meu passaporte teórico e o discurso docente o meu objeto de análise e reflexão. Busco explicitar as motivaçoes cognitivas e interacionais em competição no espaģo de sala de aula com o propósito de mostrar como a força das palawras já está prevista na "experiência" ou modelo de contexto que cada um traz dentro de si, o que deve ser levado em conta na ação pedagógica.

PaLAVRAS-CHAVE: Contexto; Cognição; Interaçãa); Análise do Discurso. 


\section{Introdução}

Enfocar a força da palavra na construção do clima organizacional da escola, mais especificamente no espaço de sala de aula, implica direcionar o objetivo deste artigo rumo a reflexões voltadas para alguns parâmetros teóricos que balizam a noção de contexto. A exemplo de uma teoria do texto, ou do discurso, uma teoria do contexto apresenta-se como proposta bastante complexa, o que tem demandado constante busca e elaboração de princípios em várias disciplinas das ciências humanas e sociais, conforme observa T. van Dijk (2001: 70), em seu artigo "Algunos princípios de la teoria del contexto".

As reflexões aqui registradas procedem de postura crítica tomada dentro da análise do discurso vista não só como corrente lingüística, mas, também como método de estudo. A análise do discurso que enfoca a língua como prática social constitui meu passaporte teórico, e o discurso - concebido como modo de ação das pessoas (sobre o mundo e sobre outras pessoas), bem como uma forma de representação de significação (que constitui e constrói o mundo), como propõe Norman Fairclough (2001) - embasa o escopo do artigo, cujo objetivo central é explicitar as motivações cognitivas e interacionais que costumam ocorrer no espaço de sala de aula.

Os pressupostos teóricos considerados envolvem uma concepção de contexto associada a modelos cognitivos interiorizados, enquanto o objeto empírico observado encontra-se constituído por episódios de uma aula gravada em vídeo em que se pode analisar a interação dialógica entre docente e discentes. Nessa perspectiva, busca-se descrever e interpretar suas expectativas mútuas, visando à aproximação aos esquemas mentais subjacentes ao discurso de cada um. Trata-se de estudo qualitativo de natureza etnográfica, cujos passos são guiados pelos procedimentos metodológicos da etnografia crítica proposta por Jim Thomas (1993). A etnografia crítica refere-se ao processo reflexivo de escolha entre alternativas conceptuais e de julgamento de significados e métodos, principalmente para desafiar a pesquisa e o monitoramento, ou policiamento, entre outras formas da atividade humana.

$\mathrm{O}$ artigo encontra-se dividido em três partes. A primeira trata da noção de contexto; a segunda aborda questões pertinentes a motivações cognitivas e interacionais; e a terceira discute os resultados de análise das 
categorias que mais se destacaram, envolvendo dados reais colhidos no espaço de sala de aula, este por sua vez enxertado em um "contexto de cultura".

\section{A noção de contexto}

Apesar do uso corrente e recorrente da noção de "contexto" na lingüística e, particularmente, nos estudos do discurso, não existe ainda na literatura aparato teórico completo que dê conta do termo plurifuncional, coinado por Malinowiski (1923, 1925 apud Halliday \& Hasan 1989), para quem um "contexto de situação" serviria para nortear a descrição e a interpretação de idéias de outra cultura, que não a do pesquisador, enquanto o termo "contexto de cultura" apontaria para a necessidade de busca que desafia qualquer investigador a ir mais além do contexto imediato. Essa segunda dimensão do termo, de acordo com Halliday \& Hasan (1989) é buscada com o objetivo de prover informações sobre o contexto cultural, visto principalmente como espaço de interação lingüística, onde ocorre o intercâmbio social de significados. ${ }^{1}$ Tal intercâmbio, veiculado na maioria das vezes por palavras, pode ser analisado principalmente, mas não exclusivamente, mediante o sistema discursivo, o qual, por sua vez, abriga as negociações intersubjetivas que fazem da língua um contrato social. ${ }^{2}$

Buscar a força da palavra nas estruturas pertinentes ao sistema discursivo, ainda que seja em um evento de sala de aula como será ilustrado adiante, remete à necessidade de indagar já de início quais são as categorias do contexto que têm influência sistemática sobre as estruturas do discurso. De acordo com T. Van Dijk (2001: 73), entre as categorias do contexto que se refletem na arquitetura do discurso, destacam-se as seguintes: aquelas que envolvem um domínio geral (ciência, meios, educa-

\footnotetext{
1 Além da tradição hallidiana da lingüística funcional sistêmica, cabe aqui registrar que o "contexto" constitui categoria fundamental nos estudos da etnografia da comunicação (Duranti e Goodwin 1992), nos estudos de Gumperz (1982), bem como no trabalho clássico de Del Hymes (1962), relacionado às situações comunicativas.

2 Para Carlos Franchi (1976 apud Castilho, 1993), a língua compreende três sistemas articulados pelo léxico: o sistema discursivo, o sistema semântico e o sistema sintático. Para Franchi, não existem relações de determinação entre esses três sistemas, que estão apenas associados, devendo ser concebidos de tal forma que cada um tenha existência autônoma.
} 
ção); aquelas que representam atos globais (como 'legislar', 'dar aulas'); aquelas que caracterizam os diversos tipos de participantes em determinada situação de interação, bem como seus papéis comunicativos (falante e/ ou ouvinte) e sociais (homem, mulher, criança, adulto, professor, aluno, etc.). Somam-se a essas categorias vários tipos de cognição que refletem conhecimentos, opiniões e objetivos entre outras pistas cognitivas materializadas no discurso, instância em que ocorrem efetivamente os processos de produção e compreensão de sentidos.

$\mathrm{Na}$ realidade, mais que pistas cognitivas, os conhecimentos, as opiniões e os objetivos, bem como as atitudes dos falantes, remetem a uma noção que merece ser aqui pontualizada. Trata-se de apontar o que se pode definir como contexto para seguir nas reflexões que permitem alcançar o que se passa no espaço de sala de aula em termos de motivações cognitivas e interacionais. Para tanto, cabe aqui registrar um conceito citado por Marcuschi (2002: 9), colhido em Kerbrat-Oricchioni (1996):

Contexto não é uma coleção de fatos materiais ou sociais t...) mas um número de esquemas cognitivos sobre o que é relevante para a interação a cada ponto dado e a cada momento (...). Esses parâmetros contextuais emergentes referem-se a fatos de conbecimento que devem ser revertidos das disposições cognitivas 'invisiveis' dos participantes em bases acessiveis coletivamente em que se conduz a interação.

A concepção proposta pelos autores mencionados anteriormente permite lembrar que constitui categoria básica de um modelo mental de contexto o conhecimento real dos participantes. Isso porque, como bem observa van Dijk (2001:73), o falante em uma situação de interação tem um "modelo de conhecimento" com respeito a seus interlocutores, ou seja, o "público". Ao que parece, é justamente esse modelo mental invisível de conhecimento que mantém o controle da informação que um falante inclui na representação do discurso. Nessa perspectiva, os modelos internalizados de contexto, que cada um possui, podem controlar a produção e a recepção de tal maneira que a estrutura do discurso seja "adequada" ou "apropriada" à situação interpessoal ou social.

Assim, em um evento de sala de aula, que inclui principalmente, ainda que não exclusivamente, a relação professor/alunos, cada participante tem a própria interpretação da situação social em que participa. Visto des- 
sa maneira, o contexto, mais do que exterioridade, remete à esfera do domínio cognitivo que envolve toda e qualquer atividade humana. E, o que mais cabe ressaltar, o contexto engloba sempre processos mentais por meio dos quais o homem gera sentido(s) e linguagem.

Por outro lado, cabe aqui registrar que, de acordo com Graesser et alii (2000: 418), "as representações semânticas na mente humana são bastante elaboradas porque estão ancoradas em um rico corpo de experiências e conhecimento geral de mundo (que varia de uma pessoa para outra)." Nessa perspectiva, pode-se vislumbrar, no espaço de sala de aula, um contexto interacional, ao mesmo tempo coletivo, pessoal e cognitivo, uma vez que cada um dos participantes (professor e alunos) tem a própria interpretação a partir dos papéis comunicativos que todos são levados a assumir de acordo com motivações cognitivas e interacionais, questões que serão tratadas a seguir.

\section{Motivações cognitivas e interacionais em competição}

À lingüística que cuida do discurso interessa não só o aspecto funcional da linguagem, mas também os processos cognitivos somados aos recursos interacionais que utilizam os interlocutores na produção e na compreensão da linguagem (Silva 2002). Tais processos ocorrem mediante a ação recíproca de pressões funcionais entre motivações cognitivas e interacionais que geralmente entram em competição, mas não de modo exclusivo, visto que podem apresentar congruência ou convergência, gerando uma espécie de padrão que garante, por sua vez, modelos cognitivos de contexto os quais envolvem, de certo modo, aspectos pessoais e sociais da situação comunicativa.

Com relação aos aspectos pessoais e sociais, Teun van Dijk (2001: 72) comenta o seguinte: "como todos os modelos mentais, o modelo de contexto não representa todos os aspectos pessoais ou sociais da situação comunicativa, mas somente os aspectos que em um dado momento são relevantes para cada participante." Por outro lado, sempre segundo van Dijk, um modelo de contexto é dinâmico, uma vez que varia durante a comunicação, devido a mudanças na situação social, ou, ainda, na interpretação do discurso. Sintetiza o referido autor que um modelo representa o que se pode deno- 
minar, ainda que de maneira informal, de "experiência", o que justifica, a meu ver, o caráter dinâmico.

As motivações cognitivas e interacionais podem entrar em competição sempre que os participantes de um evento comunicativo interpretarem a situação real mediante a construção cognitiva de uma relação entre o discurso do outro e a situação social esperada. Em outras palavras, as representações mentais que se tem de uma situação podem colidir com a realidade do momento social vivido, o que será ilustrado a seguir.

\section{Um evento de sala de aula ${ }^{3}$}

Os dados que compõem esta seção envolvem três episódios que foram gravados em vídeo durante uma aula sobre composição de textos, impartida por um professor de redação para uma turma formada por jovens, alunos de terceiro ano do segundo grau de uma escola pública, situada em uma cidade satélite próxima a Brasília. ${ }^{4}$ Observe-se que a situação socialcomunicativa ilustrada na interação dialógica assimétrica que se desenvolve entre o professor e alguns alunos revela, já de início, a ausência de ação pedagógica de controle ou monitoramento de classe. Sabe-se que, em geral, ser ouvido é uma condição que depende do capital de autoridade que o falante detém. Nesse sentido, observemos o episódio (1), que ilustra como as motivações cognitivas e interacionais podem ser identificadas por meio do discurso visto como prática social. O professor $(\mathrm{P})$, anunciando para os alunos (A1, A2, A3 e outros) que falará sobre o tema "dissertação", inicia a aula:

\footnotetext{
Convenções de transcrição dos dados orais, adaptadas de Silva (2001): alongamento de vogal (:), alongamento maior de vogal (::); parada brusca (/); pausa (...); entonação média (,); entonação ascendente de exclamação(!); entonação ascendente de interrogação (?); entonação descendente (.); transcrição parcial ou suprimida (/.../), comentários do analista ((registrados dentro de um par de parênteses)).

4 Um episódio configura uma unidade semântica (passível de ser delimitada lingüisticamente quanto ao começo e/ou fim), podendo ser definido em termos de "unidade temática" (Van Dijk 2000).
} 
EPISÓDIO 1: Caracterizando o gênero dissertativo

P: Bom, normalmente... a dissertação é entendida... estão acompanhando, não é mesmo? ((A turma conversa.))

A1: Vai ter aula?...

P: Vou te dar uma página pra estudar...

((O professor se dirige à aluna que tentou

interromper sua fala com uma brincadeira))

P: Xá mi vê:: a introdução é o prenúncio du que será discutidu, argumenta.../como se diz o::sei lá... introdução é pra introduzir.. Vamos lá?... desenvolvimento...o desenvolvimento é a argumentação. Eu estou falando, argumentando com vocês....

((Tom de censura, já que turma conversa.))

P: Bom, agora vou explicar, pode ser?... a turminha ai do fundo... posso explicar, posso explicar?... É assunto de prova... Pensem na nota...Cida, Cida... senta aí!...

((A aluna se aquieta meio constrangida.))

P: Sim, é preciso tê argumentu, se posicioná a favor ou contra. No fundo, no fundo, esse posicionamento... Oi, ô.: Carlos... isso irrita, né?... tá atrapalhando...

((Impaciência evidenciada no tom de voz do professor))

P: Quando nós nos posicionamos a favô ou contra, por exemplo... a cateirinha da escola, ou melhor, a caderneta ...você é a favô ou contra?... A caderneta é um documento que a escola utiliza pra controlar a freqüiencia dos alunos e assim poder acompanhar esse aluno mais de perto.

O episódio em destaque permite identificar momentos de um processo interacional em que os gestos comunicativos aparecem impregnados de significados os quais, por sua vez, sinalizam de maneira clara o que provoca, por exemplo, a atitude da aluna (A1) que interrompe a fala do professor (P). Sabe-se que, no processo de interação, levamos conosco os atributos que conquistamos. E, em uma situação de sala de aula, são justamente esses atributos que contribuem para fortalecer a autoridade de um professor ao exercer o seu papel social na ação pedagógica. O episódio em questão evidencia que o professor não detém conhecimento suficiente para transmitir com clareza, pelo menos durante aquela aula, o que vem a ser uma dissertação. Se todo ato de fala é um índice de identidade, os dados em análise permitem inferir que a fala do professor colide, no caso, com o seu papel social de detentor do saber. Isso implica desvio nas expectativas ou nos modelos mentais que se tem da imagem docente. E, aos alunos mais jovens, isso não passa de largo. Daí a pergunta, quiçá matizada de ironia, da aluna: - Vai ter aula?

Por outro lado, mais que um gesto comunicativo matizado de ironia, pode-se ponderar que o fato de o professor revelar atitude insegura, du- 
rante a exposição de um tema, gerou a motivação que provocou a conduta não só da jovem, mas também de seus colegas que conversavam apesar dos apelos do professor. Nas palavras de Paulo Freire (1996: 108):

Não posso ser professor sem me pôr diante dos alunos, sem revelar com facilidade ou relutância minha maneira de ser (...). Não posso escapar à apreciação dos alunos. E a maneira como eles me percebem tem importância capital para o meu desempenho.

As afirmativas de Freire acenam para um caminho reflexivo mediante o qual a análise das motivações cognitivas e interacionais poderia auxiliar o professor na remodelação de sua prática pedagógica para melhor rendimento escolar. Além do mais, a maneira como o professor se apresenta e conduz a aula tem importância direta no comportamento dos alunos, como ilustra o episódio (2) abaixo.

EPISÓDIO 2: Negociando papéis sociais

/.../

P: Atenção crianças!...

((O Professor usa um tom de voz peculiar, diferente do que vinha empregando no Episódio 1))

A2: Aí você pegou fundo, também não precisa exagerar, poxa!...

((Interpelação de um aluno.))

P: Conversas/ o professor pedindo silêncio... conversa na hora da explicação...isso são atitudes de criança...

(( O Professor tenta mitigar a impaciência, justificando sua atitude de dirigir-se aos jovens, chamando-os de crianças.))

P: Tá dando pra pegar a explicação?...Tem certeza?... Eu estou no bom caminho?... Se tiver no caminho ruim cês podem falar...Tão entendendo minha fala, o qu'eu tô falando?

((Tom mais firme de voz mantém a atenção dos alunos que passam a interagir com o professor ))

A3: Tá, tá legal!

A4: Eu tô entendendo sim.

P: Outra coisa, eu não sou dono da palavra não... Vocês podem sugerir, podem ponderar dentro da cidadania, dentro do respeito. Dentro da amizade... crítica eu aceito.

((Pouco a pouco o silêncio vai-se instalando))

P: Vocês precisam ter mais cuidado com a redação, levar mais a sério... a redação elimina...Você pode tirar a nota que for nas outras...perdeu na redação, perde o ano.

((Nova onda de impaciência gerada pela mudança

de foco no discurso))

P: Olha a reprovação, muita gente pode ser reprovada....

((E o burburinho recomeça na sala de aula $))$ 
Evidenciadas nas conversas paralelas ao discurso de exortação do professor, as atitudes de falta de atenção dos alunos podem ser interpretadas como reação contra o comportamento comunicativo instável. Observe-se que houve um desvio de foco por parte do professor, o qual deveria ensinar redação e não caracterizá-la como ferramenta para pressão psicológica. A reação dos interlocutores repalda a concepção de contexto que abarca, por sua vez, o conhecimento real dos participantes quanto ao fato de perceberem que o professor se afasta do foco central da aula.

Por outro lado, afastar-se da imagem que lhe cabe no espaço de sala de aula significa, no caso do professor em questão, perder oportunidade de se coadunar com o modelo mental "invisível" de conhecimento que, provavelmente, cada um de seus alunos possui. Isso equivale a distanciar-se dos papéis sociais que - se espera - sejam cumpridos em uma situação controlada por motivações cognitivas e interacionais. O episódio (3), apresentado a seguir, ilustra essas considerações.

EPISÓDIO 3: Finalizando a aula

/.../

P: Olha a conversa, olha a conversa... Agora eu tô falando, veja só... o que é que a professora não vai pensar de mim e de vocês também?...

((Primeira e única alusão à presença da pesquisadora naquela aula))

P: Atenção aíl atenção, galera!...

((Alunos já arrumam o material dentro das mochilas))

P: $\quad$ Simons, acho que você tá querendo...só pode ser... seguinte, dá pra parar?...

((Tentativa sem êxito de controle de disciplina))

P: Vamos dá dicas de outros tipos de desenvolvimento depois. Agora...

((A campainha toca, sinalizando término de horário))

P: Bejim,bejim/tchau, tchau!..

((Acena para todos, saindo rapidamente))

O episódio acima constitui mais uma evidência de motivações cognitivas e interacionais em competição devido aos mencionados parâmetros contextuais emergentes. Como se pode observar, esses parâmetros, refletidos principalmente na fala do professor, evocam ao mesmo tempo o conhecimento de mundo, os interesses imediatos e as expectativas de cada participante no processo interacional. 


\section{Considerações finais}

Buscou-se discutir, neste estudo, algumas pistas que conduzem às motivações cognitivas e interacionais, presentes no clima organizacional da escola e concretizadas na fala não só do professor como também de alunos. O ponto de partida foi uma revisão, ainda que sucinta, da noção de contexto, o que permitiu aproximar respostas voltadas para uma dimensão pouco explorada do contexto, visto também como espaço mental interior.

A análise dos dados colhidos dentro de um espaço ecológico por excelência, ou seja, o âmbito de sala de aula, sugere que as atitudes dos falantes constituem aspecto fundamental. Trata-se de categoria que permite identificar, através das práticas discursivas e sociais refletidas nos usos lingüísticos, a competição de motivações cognitivas e interacionais quando a realidade do momento compartilhado dentro de sala de aula fugir às expectativas, ou "experiência", de cada interlocutor.

Como esclarece van Dijk (2001: 73), não é a situação sócio-comunicativa em si que influencia as estruturas discursivas, mas a representação mental que cada participante tem da situação vivida. Isso remete à necessidade de refinar a concepção de contexto. Mais que algo externo, ou visível, o contexto deve ser compreendido em sua dimensão de interioridade, construída pelos interlocutores em termos do que é individual e subjetivo.

Registro, ao final, uma reflexão crítica sobre as práticas em sala de aula, a partir de uma indagação de Paulo Freire (2002: 34): "por que não estabelecer uma necessária 'intimidade' entre os saberes curriculares fundamentais aos alunos e a experiência social que eles têm como indivíduos?". Tal questionamento permite reiterar que o significado do que se passa em sala de aula já está previsto na "experiência" ou modelo de contexto que cada um traz dentro de si, o que deve ser levado em conta na ação pedagógica.

Uma consideração a mais se faz necessária: ao professor cabe a arte de coadunar a sua imagem, contida no modelo de contexto do qual faz parte, com o papel de pedagogo crítico capaz de modelar suas atitudes e seu discurso, abandonando o jogo do poder que está por trás da linguagem que utiliza. Para finalizar este artigo, faço minhas as palavras de Kanavillil Rajagopalan (2002: 214) para quem:

No fundo, o trabalho do pedagogo crítico é um trabalho eminentemente lingüístico, à medida que o poder se instala e se estrutura mediante a linguagem - sendo que o educador, no caso, 
sabe muito bem que é intervindo na própria linguagem que se pode intervir na realidade que se quer alterar.

E-mail:denize@solar.com.br

\section{REFERÊNCIAS Bibliográficas}

FreIre, P. 2002. Pedagogia da autonomia: saberes necessários à prática educativa. $22^{\mathrm{a}}$ ed. Rio de Janeiro: Ed. Paz e Terra.

Fairclough, N. 2001. Discurso e mudança social (Izabel Magalhães, coord. da trad., revisão técnica e prefácio). Brasília: Ed. Universidade de Brasília.

Graesser, A. C., Gernsbacher, M.A. e Goldman, S. R. 2000. Cognición. In: Teon van Dijk (org.) El discurso como estructura y proceso. Barcelona: Gedisa: 417-452.

Halliday, M.A.K. \& Hasan, R. 1989. Language, context, and text: aspects of language in a social-semiotic perspective. $2^{\mathrm{a}}$ edição. Oxford: Oxford University Press.

Kerbrat-Orecchioni, C. 1996. Text et Context. SCOLA - Sciences cognitive, Linguistique E Intelligence Artificielle 6: 39-60.

Marcuschi, L. A. 2002. Discurso, cognição e gramática nos processos de textualização. Mimeo apresentado no VI Encontro de Interação em Linguagem Verbal e Não-Verbal. Brasília: UnB.

Rajagopalan, K. 2002. Teorizando a resistência. In: D. E. G. da Silva e J. A Vieira (orgs.) Análise do discurso: percursos teóricos e metodológicos. Brasília: UnB. Oficina Editorial do Instituto de Letras; Ed. Plano: 203-220.

SILVA, D.E.G. 2002. Discurso e gramática: motivações cognitivas e interacionais. Mimeo apresentado no VI Encontro de Interação em Linguagem Verbal e Não-Verbal. Brasília: UnB.

.2001. A repetição em narrativas de adolescentes: do oral ao escrito. Brasília: Ed. Universidade de Brasília; Plano Editora; Oficina do Instituto de Letras - UnB.

Thomas, J. 1993. Doing critical ethnography. In: Qualitative Research Methods, série 26. Londres: Sage Publication.

VAn Dijk, T. 2001. Algunos principios de la teoria del contexto. In: Revista Latinoamericana de Estudios del Discurso, 1. Venezuela: Editorial Latina: 69-81.

. 2000. Episódios como unidades de análise do discurso. In: Ingedore Koch (org.) Cognição, discurso e interaçãa. $3^{\mathrm{a}}$ ed. São Paulo: Contexto: 99-121. 